\title{
Implementasi Diagram Tree pada Rancang Bangun Sistem Informasi Bebayuhan Oton Berbasis Web
}

\author{
Ni Putu Ratna Gangga Dewi ${ }^{1}$, Oka Sudana ${ }^{2}$ I Made Sukarsa ${ }^{3}$ \\ 1,2,3Program Studi Teknologi Informasi, Fakultas Teknik, Universitas Udayana \\ Kampus Unud, Bukit Jimbaran, Bali, Indonesia-803611 \\ ${ }^{1}$ ratnagangga@gmail.com \\ 2agungokas@unud.ac.id \\ 3sukarsa@ee.unud.ac.id
}

\begin{abstract}
Abstrak
Bebayuhan Oton merupakan upacara yang dipercaya Umat Hindu di Bali dapat menetralisir pengaruh negative, meliputi watak, tabiat dan sifat pengaruh hari kelahiran menurut Kalender Bali. Upacara ini mempergunakan jenis upakara yang disebut dengan banten. Banten bayuh oton dapat diketahui dengan bertanya kepada pakar bayuh oton atau Sulinggih (Pemuka Agama di Bali), waktu yang dibutuhkan untuk melakukan persiapan upacara ini kurang efektif dan efisien. Penyebabnya yaitu sulitnya mengatur waktu pertemuan dengan Sulinggih serta kurangnya pengetahuan mengenai upacara Bayuh Oton, sehingga diperlukan sebuah aplikasi yang dapat mempermudah pencarian informasi terkait upacara Bayuh Oton serta dapat dijadikan pedoman dalam pelaksanaannya. Sistem Informasi Bebayuhan dibangun guna mempermudah masyarakat Hindu untuk mendapatkan informasi mengenai Bebayuhan Oton. Pemodelan sistem yang digunakan adalah diagram tree untuk menghubungkan prosesi Bebayuhan Oton dengan banten dan sarana yang diperlukan. Sistem ini menampilkan data prosesi, banten serta sarana sabagai pelengkap upacara.
\end{abstract}

Kata kunci : Sistem Informasi Bebayuhan Oton, Pewacakan Oton, Otonan, Budaya, Upacara Agama Hindu.

\begin{abstract}
Bebayuhan Oton is a ceremony that is believed in Balinese Hindu can neutralize the negative influence of someone's birth day including the character, nature and behaviour according to the Balinese Calendar. This ceremony uses a kind of upakara (ceremony tools and equipment) called banten. Banten bayuh oton or bayuh oton ceremony equipments can be known by asking bayuh oton expert or Sulinggih (Religious Leader in Bali). However, the time needed to prepare this ceremony is less effective and efficient. The reason is the difficulty of arranging the meeting time with the Sulinggih and the lack of knowledge about bayuh oton ceremony, so it needed an application that can facilitate the search of information related to bayuh oton ceremony also can be used as guidance in the implementation of the ceremony. The information system about bebayuhan was built to facilitate Hindus' community to obtain information about bebayuhan oton. The modeling system used is a tree diagram to connect the procession of bebayuhan oton ceremony with banten and other necessary tools. This system displays the data including the procession, banten as well as the facilities as a complement ceremony
\end{abstract}

Keywords : Bebayuhan Oton Information System, Pewacakan Oton, Otonan, Culture, Hindu ceremony. 


\section{Pendahuluan}

Implementasi teknologi informasi dibidang budaya Bali dan agama masih relatif jarang dibuat. Upacara Yadnya yang ada di Bali merupakan salah satu hal menarik dibidang budaya dan agama. Penelitian yang menggabungkan budaya Bali dengan teknologi dilakukan guna menambah pengetahuan tentang budaya yang ada [1]. Upacara merupakan wujud aktivitas keagamaan, yaitu berupa kegiatan manusia dalam mendekatkan dirinya kepada Tuhan, untuk menyatakan rasa bersyukur, memohon tuntunan, maaf dan keselamatan [2]. Pelaksanaan upacara keagamaan yang sangat besar di Bali menuntut umat Hindu untuk bisa memahami halhal yang berkaitan dengan upacara Yadnya [3].

Upacara Otonan merupakan salah satu contoh dari pelaksanaan upacara Manusia Yadnya. Upacara Otonan merupakan upacara peringatan hari kelahiran berdasarkan Kalender Bali yang dilaksanakan setiap 210 hari atau 6 bulan sekali,tujuannya untuk penyucian lahir batin [4]. Otonan didasarkan pada pertemuan Wewaran dan Pawukon yang dapat memberikan pengaruh negatif terhadap sifat, watak dan perilaku seseorang, menurut tradisi Hindu di Bali ramalan ini disebut dengan Pewacakan Oton. Pewacakan oton dapat memberikan gambaran masing-masing sifat negatif yang dapat dikurangi atau menetralisirnya dengan melaksanakan upacara Bayuh Oton. Waktu yang dibutuhkan untuk melakukan persiapan upacara ini kurang efektif dan efisien dikarenakan sulitnya mengatur waktu pertemuan dengan Sulinggih (Pemuka Agama di Bali), sehingga untuk mempersingkat waktu persiapan diperlukan sebuah aplikasi yang dapat mempermudah pencarian informasi terkait upacara Bayuh Oton serta dapat dijadikan pedoman dalam pelaksanaannya.

Sistem Informasi Bebayuhan Oton menampilkan runtutan data prosesi yang menggunakan sarana dan banten berbeda-beda pada setiap prosesinya. Data prosesi Bayuh Oton yang dimodelkan ke dalam struktur data tree untuk menghubungkan antara prosesi dengan sarana dan banten yang digunakan. Informasi yang ditampilkan sistem berupa foto, deskripsi serta detail banten yang dipergunakan dan perkiraan harga banten.

Diagram tree telah banyak digunakan untuk pemodelan sistem. Diagram tree digunakan untuk menampilkan informasi tentang data ulam bebantenan. Sistem informasi ini dibangun agar bisa dijalankan pada perangkat mobile dengan Sistem operasi Android Aplikasi ini memberikan informasi tentang deskripsi, teks, gambar dan video yang berhubungan dengan ulam bebantenan di Bali [5]. Diagram tree digunakan dalam pemodelan informasi Gamelan berdasarkan golongan dan informasi Gamelan berdasarkan upacara yadnya [6]. Pemodelan diagram tree digunakan dalam mengolah data kependudukan pada suatu lingkup daerah [7] dan digunakan juga untuk mengolah jenis jajanan tradisional yang ada di Bali [8]. Perbedaan penggunaan pemodelan diagram tree pada setiap aplikasi tersebut dengan aplikasi Sistem Informasi Bebayuhan Oton adalah data yang digunakan dalam pemodelan diagram tree berbeda.

\section{Metodologi Penelitian}

Metode penelitian yang digunakan adalah berupa metode pengumpulan data dan metode pemodelan sistem. Metode pengumpulan data yang meliputi studi literatur dan metode wawancara. Metode studi literatur dilakukan dengan cara mengumpulkan data dari referensi buku, jurnal maupun tugas akhir yang berkaitan dengan perancangan aplikasi Sistem Informasi Bebayuhan Oton Berbasis Web. Metode wawancara dilakukan terhadap seorang Sulinggih yang merupakan seorang pakar pewacakan maupun pakar dibidang Bayuh Oton.

Metode pemodelan sistem Bayuh Oton ditampilkan dalam bentuk diagram tree. Metode tree dapat membantu dalam menggambarkan struktur pohon dengan akar dan percabangan [7]. Struktur tree biasanya digunakan untuk menggambarkan hubungan hierarkis antara elemenelemen yang ada pada suatu sistem [9]. Pemodelan tree dari Bebayuhan Oton ini berupa diagram tree banten dan perlengkapan sarana upacara Bayuh Oton. Data Flow Diagram (DFD) digunakan untuk membantu dalam memodelkan sistem, menampilkan proses yang terjadi pada sistem. 


\subsection{Diagram Tree Bayuh Oton}

Diagram tree Bayuh Oton digunakan sebagai pemodelan sistem yang menghubungkan antara prosesi Bayuh Oton dengan banten dan sarana yang digunakan.

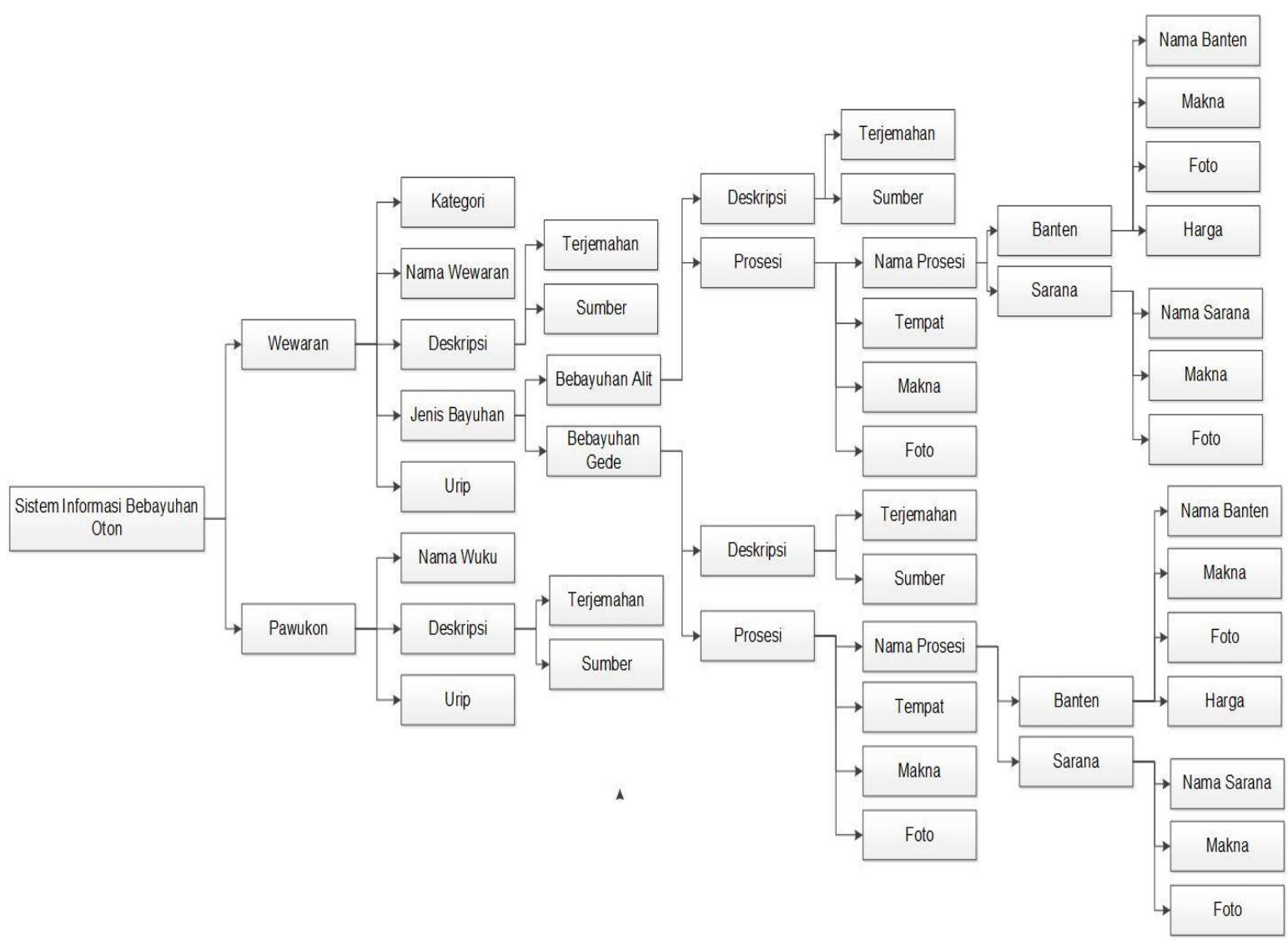

Gambar 1. Diagram Tree Bayuh Oton

Gambar 1 menampilkan diagram tree upacara Bayuh Oton. Pemodelan sistem yang digunakan adalah diagram tree untuk menghubungkan prosesi dengan banten dan sarana yang digunakan. Data prosesi menampilkan nama prosesi tempat, makna dan foto. Data sarana menampilkan nama sarana, makna dan foto. Data banten yang ditampilkan adalah nama banten, makna, foto dan harga.

\subsection{Diagram Konteks}

Diagram konteks menampilkan hubungan antara semua kesatuan luar yang terlibat didalam sistem serta dimana sebuah sistem digambarkan secara garis besar atau secara umum. Berikut merupakan diagram konteks Sistem Informasi Bebayuhan Oton. 


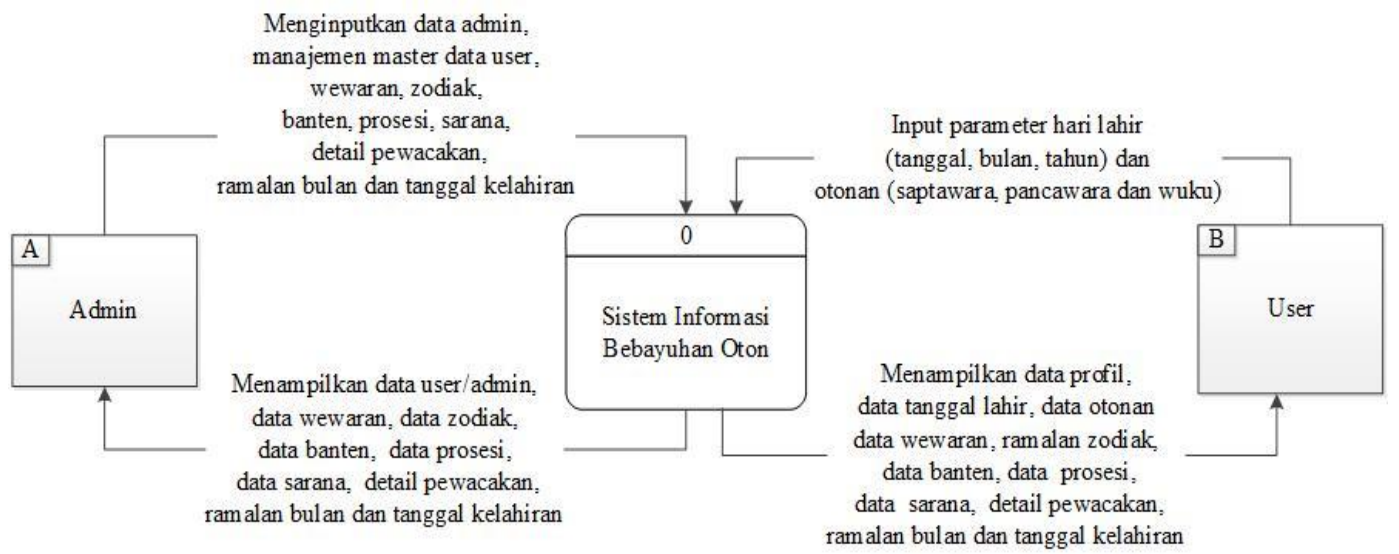

Gambar 2. Diagram Konteks

Gambar 2 merupakan diagram konteks dari Sistem Informasi Bebayuhan Oton. Entitas Admin dapat melakukan manipulasi data yang ada pada Sistem Informasi Bebayuhan Oton. Entitas user dapat melakukan input data parameter agar sistem dapat menampilkan data yang diperlukan.

\subsection{Overview Diagram}

Overview diagram memiliki 4 proses yang terdiri dari login admin atau user, manajemen master data, pencarian otonan dan pencarian tanggal lahir.

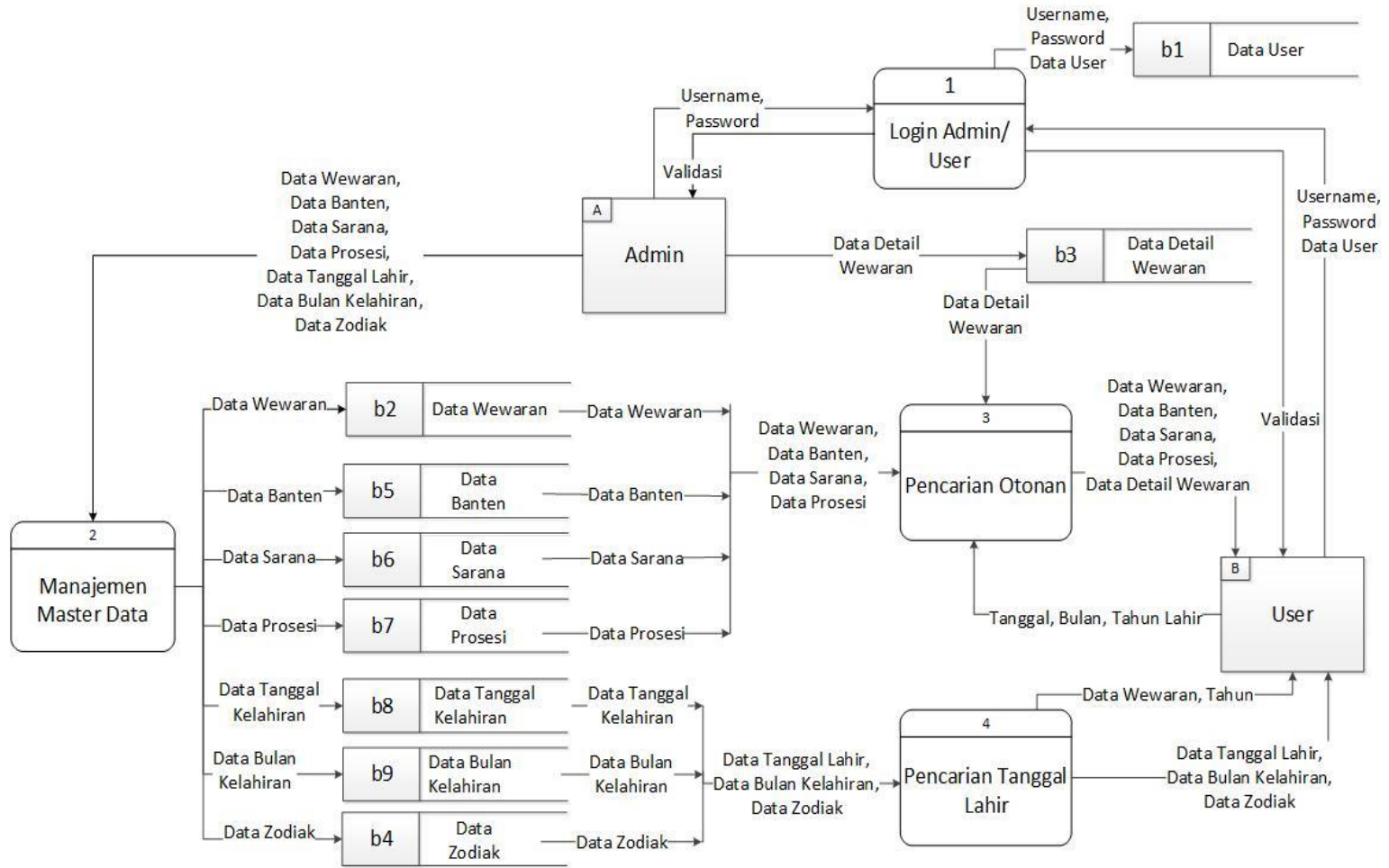

Gambar 3. Overview Diagram Sistem Informasi Bebayuhan Oton

Gambar 3 merupakan data flow diagram level 0 Sistem Informasi Bebayuhan Oton yang memiliki 4 buah proses dan 2 entitas. Proses yang ada pada sistem adalah proses login admin atau user, proses manajemen master data, proses pencarian otonan dan proses pencarian tanggal lahir Entitas yang ada pada sistem yaitu admin dan user. 


\subsection{Entity Relationship Diagram}

Entity Relationship Diagram (ERD) merupakan diagram yang digunakan untuk menggambarkan hubungan antar entitas yang memiliki atribut pada suatu sistem. Berikut merupakan gambaran Entity Relationship Diagram (ERD) pada Sistem Informasi Bebayuhan Oton.

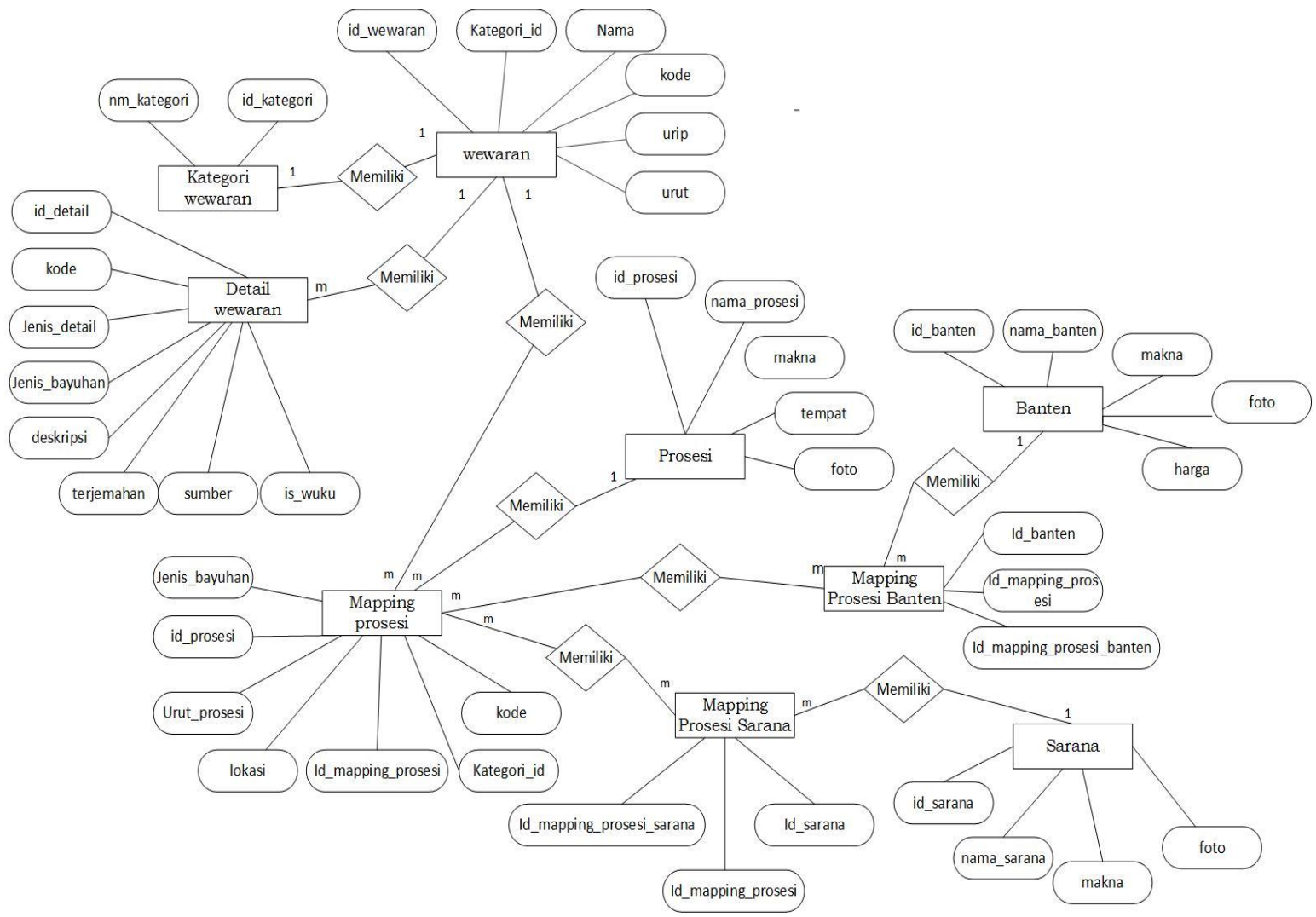

Gambar 4. Entity Relationship Diagram

Gambar 4 merupakan Entity dan Relationship yang terlibat dalam Sistem Informasi Bebayuhan Oton. Entitas yang dimiliki berjumlah 9 yang terdiri dari wewaran, detail wewaran, prosesi, banten, sarana, mapping prosesi, mapping prosesi sarana, mapping prosesi banten.

\section{Kajian Pustaka}

Kajian pustaka berisi teori-teori yang digunakan sebagai penunjang penelitian dan pemecahan masalah dari penelitian yang dibuat.

\subsection{Sistem Informasi}

Sistem informasi adalah seperangkat komponen yang memiliki keterkaitan antara satu dan lainnya serta memiliki fungsi untuk mengumpulkan, memproses, menyimpan, dan mendistribusikan informasi [10]. Informasi yang dimaksudkan adalah kumpulan dari data yang telah diolah menjadi suatu bentuk yang nantinya dapat bermanfaat bagi manusia serta dapat digunakan dalam pengambilan suatu keputusan [11].

\subsection{Diagram Tree}

Diagram Tree merupakan metode yang digunakan untuk membuat suatu pemodelan sistem. Struktur tree memiliki ciri tertentu serta sifat khusus yang digunakan untuk menghubungkan antar elemen-elemen pada sebuah sistem [12]. 


\subsection{Otonan}

Otonan merupakan peringatan hari kelahiran berdasarkan Kalender Bali yang dilaksanakan enam bulan sekali atau 210 hari sekali. Tujuan yang ingin dicapai dari pelaksanaan upacara otonan adalah penyucian diri lahir dan bathin [4].

\subsection{Pewacakan Oton}

Ramalan hari kelahiran seseorang atau dalam tradisi Hindu di Bali disebut dengan Pewacakan. Pewacakan pewatekan oton ini berdasarkan perhitungan hari yang berjumlah 7 hari yang disebut Saptawara, perhitungan 5 hari yang disebut dengan Pancawara dan Wuku yang meliputi 30. Perpaduan Saptawara dan Pancawara menghasilkan 35 hari kelahiran manusia yang mempunyai pengaruh terhadap kelahiran seseorang yang tampak pada sifat, tabiat dan watak atau karakter dan nasib orang yang lahir pada salah satu jenis hari kelahiran tersebut. Watak, nasib baik atau buruk seseorang juga dipengaruhi oleh jenis Wuku saat dia lahir. Wuku merupakan sejenis pekan atau mingguan yang berjumlah tiga puluh jenis, setiap Wuku terdiri atas tujuh hari yang tergolong dalam hari Saptawara [13].

\subsection{Bebayuhan Oton}

Bayuh Oton adalah upacara yang diyakini dapat menetralisir derita bawaan sejak lahir. Bayuh Oton dilaksanakan tepat pada hari kelahiran yang mana berdasarkan Wuku dan Wewaran. Bayuh Oton memiliki tujuan sebagai penyucian diri, baik secara jasmani maupun rohani. Pelaksanaan Bayuh Oton juga bertujuan menetralisir bahkan menghilangkan pengaruh-pengaruh negatif meliputi tabiat buruk, penyakit, derita bawaan dan pengaruh buruk lainnya. Bayuh Oton merupakan sarana untuk membayar hutang yang dibayarkan atau ditebus dengan upakara. Bayuh Oton mempergunakan jenis upakara yang disebut banten. Banten upacara yang dipergunakan disesuaikan dengan Wewaran atau hari kelahiran, setiap Wewaran memiliki jenis banten maupun sarana yang berbeda sehingga akan ada perbedaan jenis banten. Kelahiran seseorang berbeda-beda sehingga memiliki pengaruh negatif yang berbeda-beda, maka dalam melakukan suatu proses ruwatan atau masyarakat Hindu di Bali mengenal berbagai jenis Bayuh Oton kelahiran seseorang [14]. Jenis Bebayuhan Oton yang dibahas pada Sistem Informasi Bebayuhan Oton, yaitu sebagai berikut.

a. Bebayuhan Alit

Bebayuhan Alit atau yang disebut dengan Dedinan merupakan bebayuhan yang didasari oleh pertemuan saptawara dan pancarawa kelahiran seseorang. Pertemuan saptawara dan pancawara terjadi setiap bulan, sehingga bebayuhan ini disebut Bebayuhan Alit karena memiliki lingkup yang kecil atau alit.

b. Bebayuhan Gede

Bebayuhan Gede atau yang disebut dengan Madius Kinurungan merupakan bebayuhan yang didasari oleh pertemuan sepuluh Wewaran dan pawukon kelahiran seseorang. Pertemuan sepuluh Wewaran dan Pawukon terjadi setiap enam bulan sekali, sehingga bebayuhan ini disebut Bebayuhan Gede karena memiliki lingkup yang luas jika dibandingkan dengan Bebayuhan Oton Alit.

\section{Hasil dan Pembahasan}

Hasil dan pembahasan menampilkan hasil uji coba perangkat lunak serta menganalisa aplikasi secara keseluruhan.

\subsection{Halaman Login Administrator}

Halaman login merupakan halaman yang dapat digunakan untuk melakukan proses login agar dapat mengakses Sistem Informasi Bebayuhan Oton. 
a Login

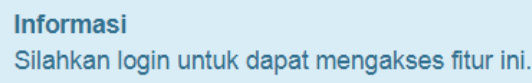

2 Create new account?

Gambar 5. Halaman Login Administrator

Gambar 5 merupakan halaman yang menampilkan form login yang digunakan untuk membatasi akses. Akses yang dijinkan hanya memiliki username dan password yang telah terdaftar pada sistem atau telah melakukan proses registrasi.

\subsection{Master Data Prosesi}

Master data prosesi digunakan untuk menampilkan dan melakukan manipulasi data prosesi Bebayuhan Oton. Berikut merupakan tampilan halaman master data prosesi.

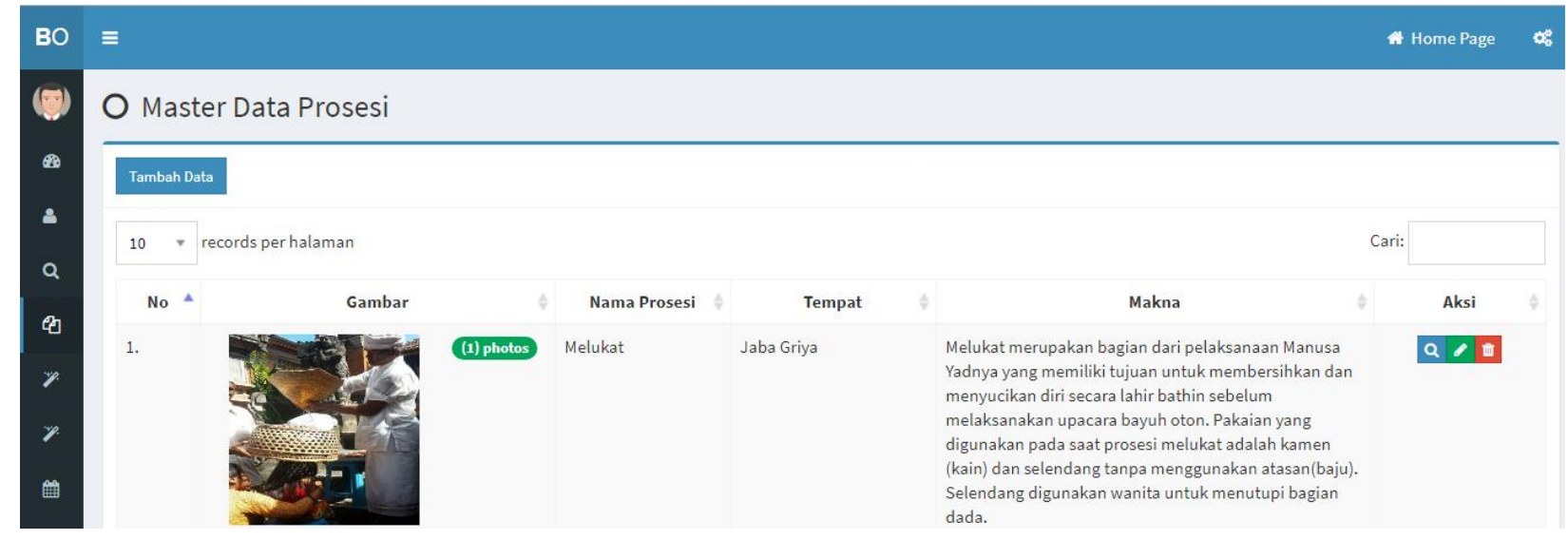

Gambar 6. Master Data Prosesi

Gambar 6 merupakan halaman master data prosesi yang menampilkan gambar atau foto prosesi, nama, makna prosesi dan tempat dilaksanakannya prosesi tersebut. Data prosesi bersumber dari upacara Bebayuhan Oton yang dilaksanakan di Griya Gede Wayahan Buruan Manuaba, Blahbatuh, Gianyar. Warna pakaian yang digunakan dalam upacara Bayuh Oton ditentukan berdasarkan hari kelahiran (saptawara).

\subsection{Master Data Banten}

Master data banten digunakan untuk manipulasi serta menampilkan data banten. Master data banten menampilkan data banten yang digunakan dalam setiap prosesi upacara Bayuh Oton. 


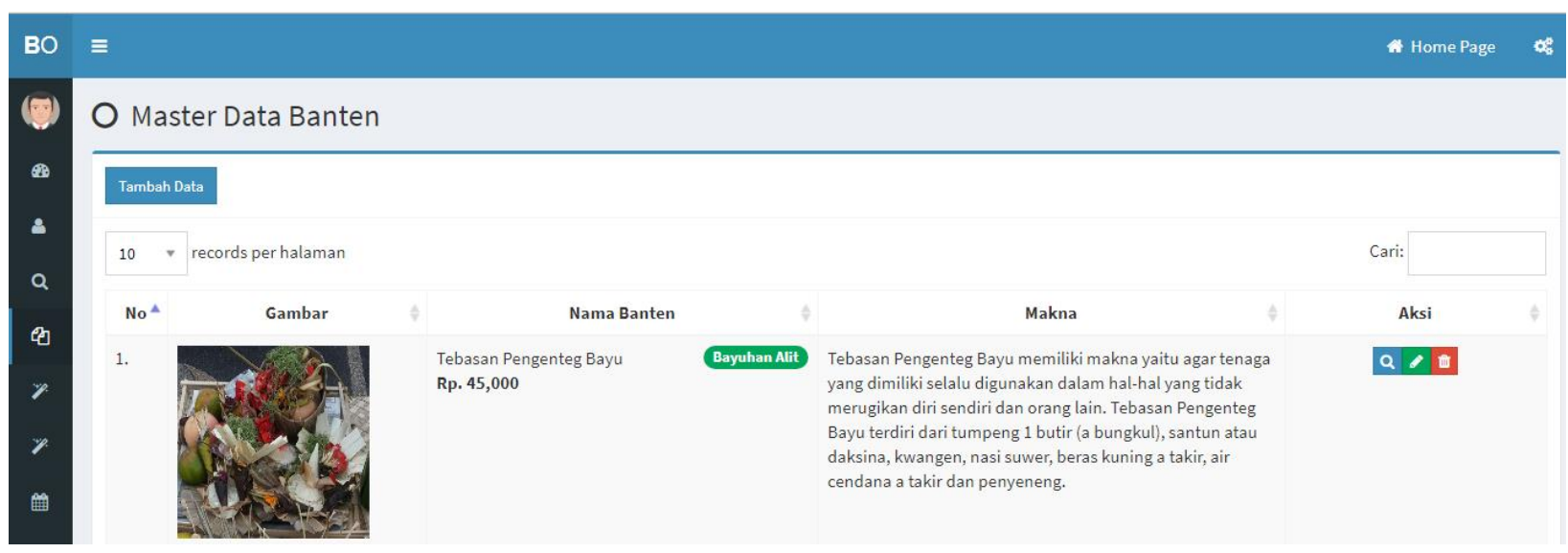

Gambar 7. Master Data Banten

Gambar 7 merupakan tampilan dari master data banten yang menampilkan foto banten, nama, makna banten yang disertai komponen yang terdapat pada banten serta harga banten. Banten bayuhan yang digunakan, ditentukan berdasarkan hari kelahiran (saptawara dan pancawara). Banten yang jadi pembeda adalah banten sesayut dimana masing-masing hari memiliki banten Sesayut yang digunakan. Banten yang digunakan dalam upacara Bebayuhan Oton menyesuaikan bentuk atau jenis bebantenan sesuai dengan desa kala patra yang berlaku di Griya Gede Wayahan Buruan Manuab, Blahbatuh, Gianyar (tempat dilaksanakanya penelitian).

\subsection{Master Data Sarana}

Master data sarana yang digunakan untuk menyimpan dan melakukan manipulasi data sarana dan perlengkapan yang digunakan dalam upacara Bayuh Oton.

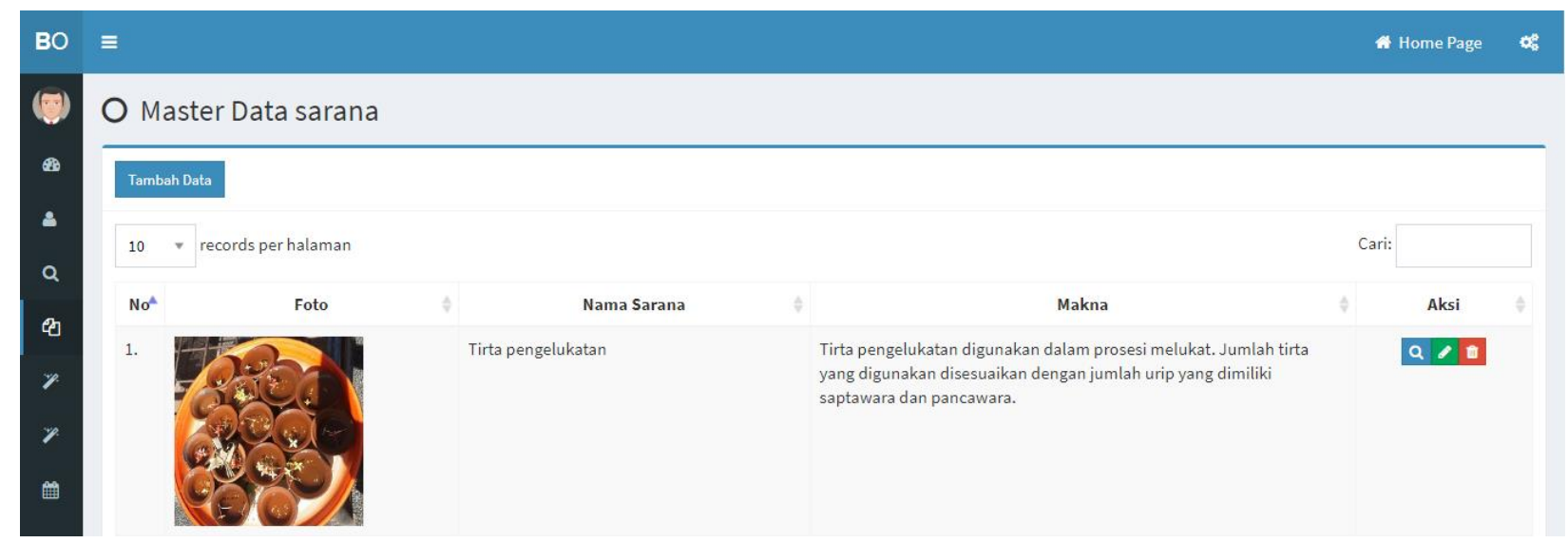

Gambar 8. Master Data Sarana

Gambar 8 merupakan master data sarana yang menampilkan gambar, nama sarana dan makna. Sarana yang digunakan dalam setiap prosesi berbeda-beda, data tersebut antara lain tirta pengelukatan, keranjang, kukusan (anyaman bambu berbentuk kerucut), danyuh (daun kelapa kering), api takep, karawista, kalpika (kartika), bija, kwangen, bunga, dupa dan bungkak nyuh gading.

\subsection{Halaman Mapping Prosesi, Banten dan Sarana Bebayuhan Oton}

Halaman mapping prosesi merupakan halaman yang digunakan admin untuk melakukan proses mapping terhadap data prosesi, sarana dan banten upacara Bebayuhan. 


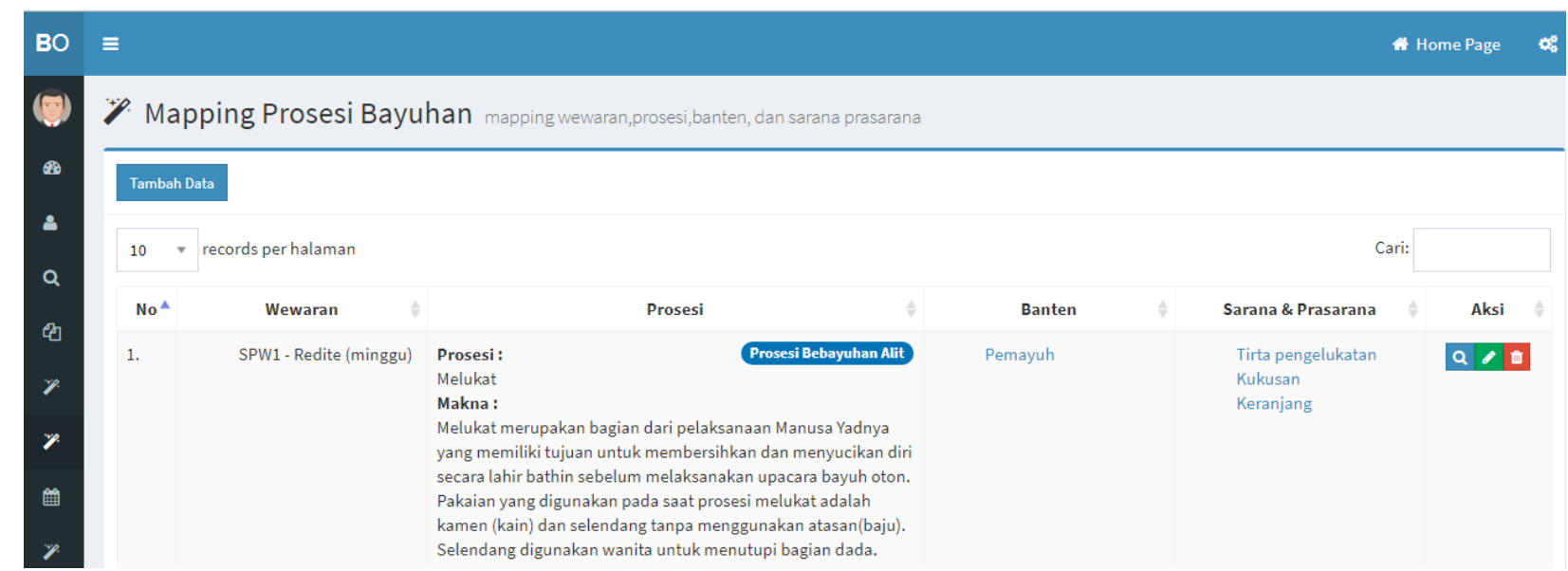

Gambar 9. Halaman Mapping Prosesi, Banten dan Sarana Bebayuhan Oton

Gambar 9 merupakan halaman mapping prosesi Bebayuhan Alit dan Bebayuhan Gede yang menampilkan data Wewaran, prosesi, banten dan sarana yang digunakan dalam upacara Bebayuhan. Informasi yang ditampilkan adalah wewaran, prosesi, banten dan sarana.

\subsection{Uji Coba Aplikasi}

Pengujian terhadap aplikasi dilakukan untuk mengetahui sejauh mana mengetahui kecepatan dalam mengakses Sistem Informasi Bebayuhan Oton melalui jaringan internet.

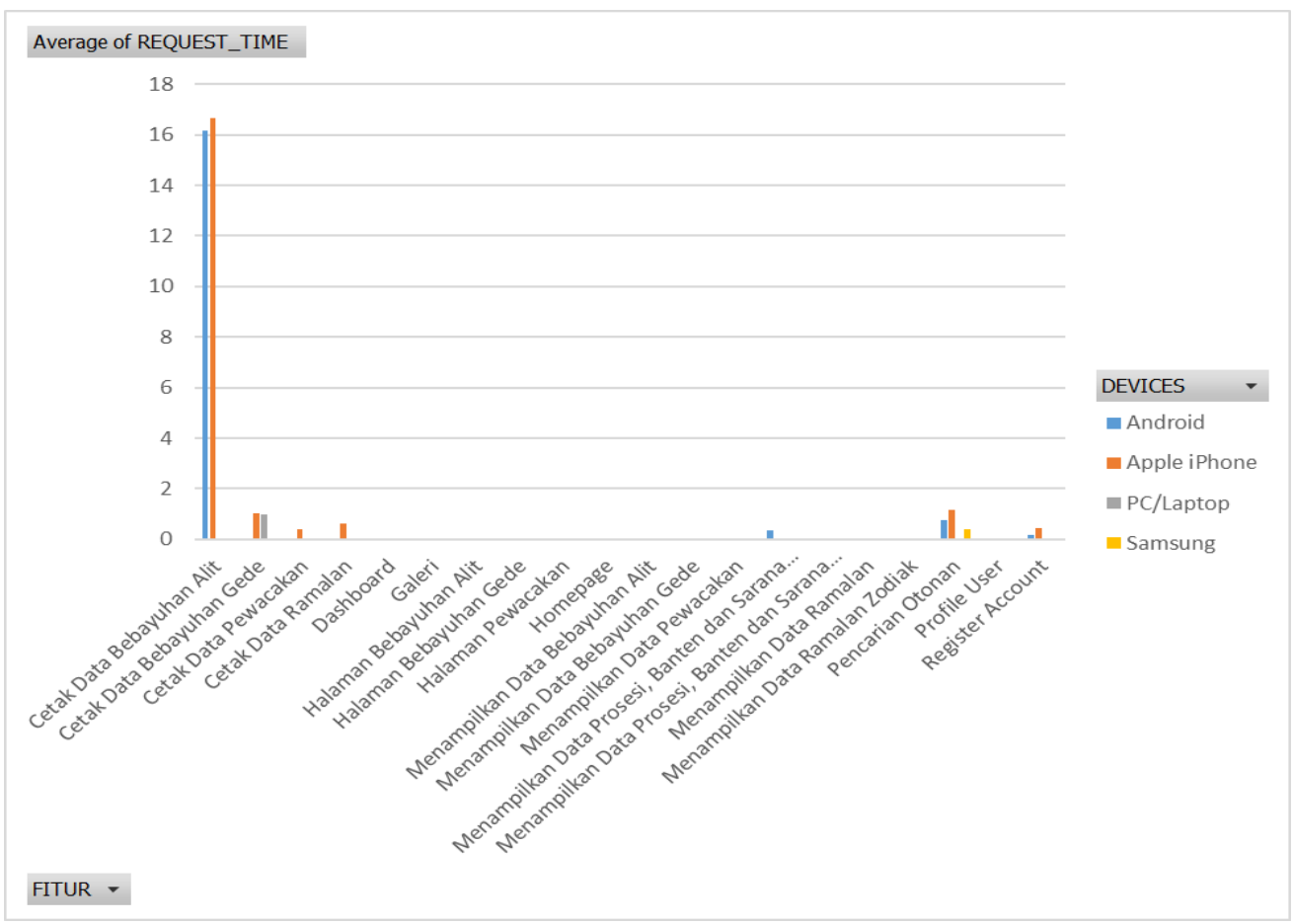

Gambar 10. Grafik Uji Coba

Gambar 10 merupakan grafik uji coba yang menghitung waktu yang dibutuhkan devices atau perangkat untuk mengakses fitur yang ada pada Sistem Informasi Bebayuhan Oton.

\section{Kesimpulan}

Kesimpulan dari hasil dan pembahasan penelitian Sistem Informasi Bebayuhan Oton yaitu, pemodelan sistem yang digunakan adalah metode struktur data pohon atau diagram tree. Metode 
ini mampu menggambarkan mapping data prosesi bayuh oton yang dihubungkan dengan banten dan sarana untuk upacara. Aplikasi Sistem Informasi Bebayuhan Oton menampilkan data sesuai dengan struktur diagram tree. Sistem ini memberikan informasi tentang prosesi upacara Bebayuhan Oton yang dilengkapi dengan banten dan sarana yang digunakan. Sistem dapat diakses pada website dengan menggunakan berbagai perangkat atau device.

\section{Daftar Pustaka}

[1] D. P. Andre Sanjaya, I. K. A. Adi Purnawan, and N. K. Dwi Rusjayanthi, "Pengenalan Tradisi Budaya Bali melalui Aplikasi Game Explore Bali Berbasis Android," Lontar Komputer : Jurnal IImiah Teknologi Informasi, vol. 7, no. 3, pp. 163-174, 2016.

[2] Oka Sudana, A.A.K. Ayu Putri, Gusti Agung. Kurnia Jayanti I. Ay. G., "Pemodelan Sistem Informasi Bebantenan dalam Kaitannya dengan Upacara Yadnya," Teknologi Elektro, vol. 8, no. 1, 2009.

[3] Oka Sudana, A.A.K. Sukarsa, I Made. Wahyu Saputra I. M., "Information System of Yadnya Ceremony on Android-Based," International Journal of Hybrid Information Technology, vol. 7, no. 6, pp. 155-164, 2014.

[4] Oka Sudana, A.A.K. Mei Sujana, I Wayan. Dwi Rusjayanthi N. K., "Arbantenotonan: A Learning Media Base On Augmented Reality Traditional Balinese," Journal of Theoretical and Applied Information Technology,, vol. 95, no. 7, pp. 1362-1369, 2017.

[5] Oka Sudana, A.A.K., Brampramana Putra A. A. G., "Tree Data Structure Implementation in Android Base System of E-Ulambebantenan," Applied Mechanics and Materials, vol. 776, pp. 431-436, 2015.

[6] Pratama, Wayan Galih. Oka Sudana, A A.K. Agung Cahyawan W A. A. K., "Pemodelan Sistem Informasi Gamelan Bali Menggunakan Tree Diagram," Merpati, vol. 2, no. 2, pp. 246252, 2014.

[7] I. G. B. Ari Pinatih, A. A. K. Oka Sudana, and I. K. Adi Purnawan, "E-Banjar Bali, Population Census Management Information System of Banjar in Bali by Using Family Tree Method and Balinese Culture Law," Journal of Theoretical and Applied Information Technology,, vol. 59, no. 2, pp. 411-420, 2014.

[8] Oka Sudana, A.A.K. Mayun Kepakisan, I Wyn Gede. Dwi Rusjayanti N. K., "Implementation of Tree Structure and Recursive Algorithm for Balinese Traditional Snack Recipe on Android Based Application," International Journal of Interactive Mobile Technologies (iJIM), vol. 10, no. 4, pp. 43-47, 2016.

[9] N. K. Riska Sadini, I. K. G. Darma Putra, and A. A. K. Oka Sudana, "Manajemen Data Sistem Informasi Bebantenan Bagian Banten / Upakara Berbasis Web," Merpati, vol. 2, no. 3, pp. 316-325, 2014.

[10] A. A. G. . Brampramana Putra, A. A. K. Oka Sudana, and I. K. Adi Purnawan, "Client-server Sistem Informasi Ulam Bebantenan," Merpati, vol. 2, no. 3, pp. 308-315, 2014.

[11] I. M. Wahyu Saputra, I Made Sukarsa. A.A.K. Oka Sudana, "Implementasi Struktur Data Tree pada Sistem Informasi Upacara Yadnya berbasis Android," Merpati, vol. 2, no. 1004505060, pp. 1-10, 2014.

[12] A. A. K. Oka Sudana, "Implementasi Struktur Tree pada Rancang Bangun Sistem Penelusuran Sejarah Pura Kawitan dan Kahyangan jagat Berbasis Web," Lontar Komputer : Jurnal IImiah Teknologi Informasi, vol. 2, no. 1, 2011.

[13] I. G. Sugata Yadnya Manuaba, "Wacakan Pewatekan Oton," Denpasar: Pustaka Bali Post, 2012.

[14] I. G. Sugata Yadnya Manuaba, Bayuh Oton. Denpasar: Pustaka Bali Post, 2013. 